\title{
Seasonal Variation in Surface Ozone Concentrations, Meteorology and Primary Pollutants in Coastal Mega City of Mumbai, India
}

Sagar A. Marathe and Shankar Murthy*

National Institute of Industrial Engineering, Mumbai, India 400087

\begin{abstract}
In the present the study variation in ground level ozone (GLO) concentration with respect to availability of precursor pollutants and meteorological parameters in the tropical climatic conditions in Mumbai, India is discussed. The concentration of various pollutants and meteorological parameters have been monitored at the continuous air quality monitoring station of Maharashtra Pollution Control Board, located in Bandra (Mumbai) for two years. The analysis of the data indicates that the pattern of formation of GLO changes with change in season. The maximum concentration for GLO was experienced in the post monsoon season unlike any other study reported in the country. The study highlights that the post monsoon season experienced the highest number of hourly and eight hourly exceedances in the permissible limits prescribed by the Central Pollution Control Board. These high concentrations can be attributed to favorable climatic conditions and presence of precursor pollutants. This was proved by correlating GLO with precursor pollutants and meteorological parameters.
\end{abstract}

Keywords: Ground level ozone; Mumbai; Air quality; Correlation of ozone

\section{Introduction}

Ozone $\left(\mathrm{O}_{3}\right)$ is a colorless and reactive oxidant gas which is a major constituent of atmospheric smog. It is secondary pollutant, which is formed due to photo-chemically active primary pollutants [1-4]. The concentration of Ground Level Ozone (GLO) pollution becoming a major concern because of its increasing concentrations and adverse impacts on plants and animals including human beings, even at low concentrations [5-7].

In order to control the ground level ozone pollution in the country, the Central Pollution Control Board (CPCB) has announced revised air quality standards in the year 2009 which include one hourly and eight hourly permissible limits for GLO for the first time in the country and have also included ozone in the list of criteria pollutants.

Furthermore literature available regarding variation of GLO in India is limited and the studies have different climatic backgrounds from rural areas to urban and sub urban regions [8-11]. Hence, the comparison is difficult. The studies which are available report observations for short duration or for one or two seasons and are mostly conducted with the objectives of assessing the impact of ambient ozone concentrations on various varieties of pollutants $[12,13]$. There is limited literature available on continuous long term monitoring for ground level ozone concentrations along with the precursor pollutants in urban as well as rural areas. The formation of ground level ozone is non-linear in nature which makes the approach to the study even more difficult. The chemistry of ground level ozone is explained in (Appendix I).

There is a dearth of studies in the Indian context; moreover such extensive studies have not been conducted for the sub-tropical climatic conditions.

After laying the basis for the study, a brief analysis of the literature is presented in section two. Section three documents the chemistry of ozone formation, while section four describes the characteristics of the sampling location. Besides, in the same section, the climatic conditions of the city are described. In addition, the prominent features are also highlighted. The fifth section discusses the methodology of the study.
The results and discussions are presented in the sixth section while the seventh/last section provides conclusions and future scope for the study.

\section{Brief Literature Review}

Clinical studies have documented an association between shortterm exposure to ground-level ozone (at concentrations of 200-500 $\mu \mathrm{g}$ / $\mathrm{m}^{3}$ ) and mild temporary eye and respiratory irritation, cough, throat dryness, thoracic pain, and headache $[5,14,15]$. Across Europe, $\mathrm{O}_{3}$ was attributed to 21,400 premature deaths per annum [16]. Against a similar back drop studies by Chameides et al. [6] documented the effects of increased ozone concentrations on crop yield and forests. In this study it was identified that high ozone concentration lead to low productivity and loss of forest cover.

Derwent analysed long-term measurements from Mace Head on the west coast of Ireland and found an increase in background ozone until 1999 and a stabilization or decline thereafter. The reasons are attributed to the rise in emissions from anthropogenic activities. For Europe, Jonson considered the period 1990-2004 and predicted reduction of $5-10 \mathrm{ppb}\left(10-20 \mu \mathrm{g} / \mathrm{m}^{3}\right)$ in mean daily maximum summer ozone concentrations (June-August).

In another study for European region, it was observed that the concentration of surface ozone had increased from an estimated preindustrial value of $10 \mathrm{ppb}$ to 30-50 ppb (Pritchard and Amthor, 2005). The results were found to be applicable for areas lying in the midlatitudes of the northern hemisphere. Kley D et al. [17] has reported

${ }^{*}$ Corresponding author: Shankar Murthy, Associate Professor, National Institute of Industrial Engineering Mumbai, India 400 087, Tel: +91-976-940-1396; E-mail: murthyshanker@gmail.com

Received November 17, 2015; Accepted December 23, 2015; Published December 29, 2015

Citation: Marathe SA, Murthy S (2015) Seasonal Variation in Surface Ozone Concentrations, Meteorology and Primary Pollutants in Coastal Mega City of Mumbai, India. J Climatol Weather Forecasting 3: 149. doi:10.4172/23322594.1000149

Copyright: @ 2015 Marathe SA, et al. This is an open-access article distributed under the terms of the Creative Commons Attribution License, which permits unrestricted use, distribution, and reproduction in any medium, provided the original author and source are credited. 
Mesoscale convective systems which contributed to diurnal variation in $\mathrm{O}_{3}$ concentration; that substantially and abruptly deviated from the diurnal patterns observed during sunny conditions enhancing the boundary layer $\mathrm{O}_{3}$ concentration by $10-30 \mathrm{ppbv}$. In the Asian context, study by Min Shao, has discussed the role of $\mathrm{NO}_{\mathrm{x}}$ and VOCs in the formation of $\mathrm{O}_{3}$ at ground level in and around the Pearl River delta (China).

From the above it can be inferred that ozone has dire consequences on not only plant and animal life but also on human existence. The present study aims to evaluate the variation in ground level ozone concentrations with respect to availability of precursor pollutants and change in seasonal climatic conditions.

\section{Methodology}

Mumbai is located in tropical zone and is known to have fluctuation in relative humidity in every season, which in turn is bound to affect the ozone formation. Being a mega city, Mumbai has large population density of over 29,000 individuals per sq. $\mathrm{km}$. This high density is likely to result in large scale ozone exposure. Hence a detailed study of formation ozone is necessary for the mega city of Mumbai. The study attains significance as this may be its first of its kind. In addition the monitoring of a secondary pollutant would allow the decision makers to capture the holistic picture of air pollutants.

\section{Meteorology}

The site experiences distinct seasons due to the tropical climatic zone. The temperature reaches peak in unison with solar intensity around 13:00 hrs. And drops to minimum during night and early morning hours in the absence of solar radiation around 03:00 hrs. The monthly average temperature recorded at the monitoring site is presented in (Figure 1). The summer season occurs between the months of March to May and is marked with very hot and humid climate with maximum temperature recorded to be $40^{\circ} \mathrm{C}$ in the month of May.

It is important to note that the relative humidity drops to minimum of $20 \%$ in the summer season. The average relative humidity is presented in (Figure 2). The relative humidity and temperature are a function of solar intensity which is also observed to be maximum during the same season. The variation of solar intensity is presented (Figure 3). As a characteristic feature of the tropical site, heavy rainfall for four months is experienced during June to September during the season. The rainfall is the result of north-west monsoon. The wind pattern for the seasons is provided in (Figure 4). Maximum rainfall is experienced in the month of July. The relative humidity in the entire monsoon season is very high. The minimum relative humidity

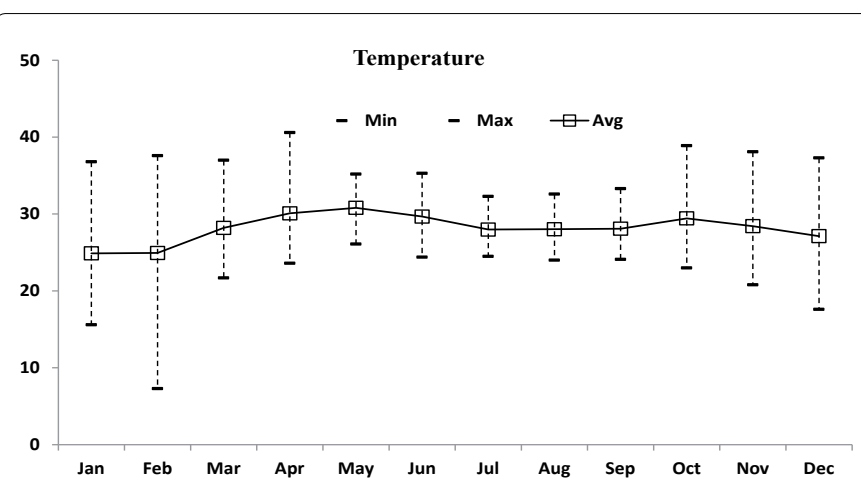

Figure 1: Seasonal variation in ambient temperature at monitoring site. recorded in this season was $57 \%$ while the maximum was $99 \%$. The average relative humidity of the season varied between $78-85 \%$. The solar intensity is observed to be intermittent and weak in the monsoon season. The monsoon season is then followed by small transitional Post-Monsoon season. The season lasts only for two months of October and November, which is distinguished by high temperatures and high humidity. The temperature shoots up in October leading to locally known phenomenon of "October Heat" during which the climate is similar to summer. The relative humidity is observed to fluctuate prominently in this season. The minimum relative humidity is recorded

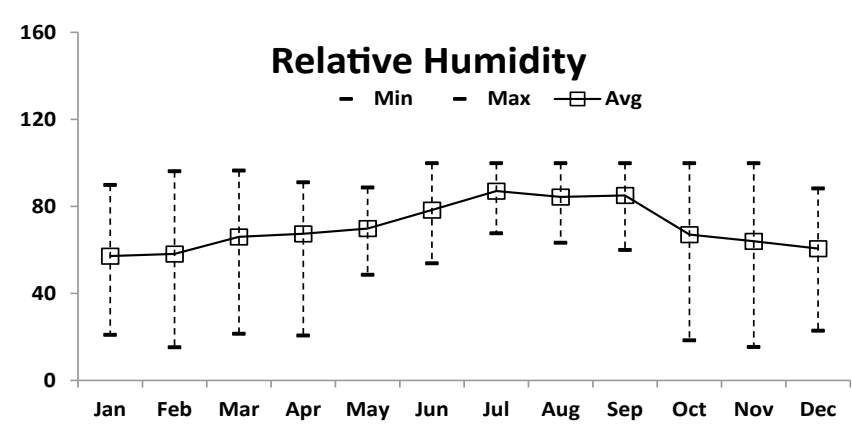

Figure 2: Seasonal variation in relative humidity at monitoring site.

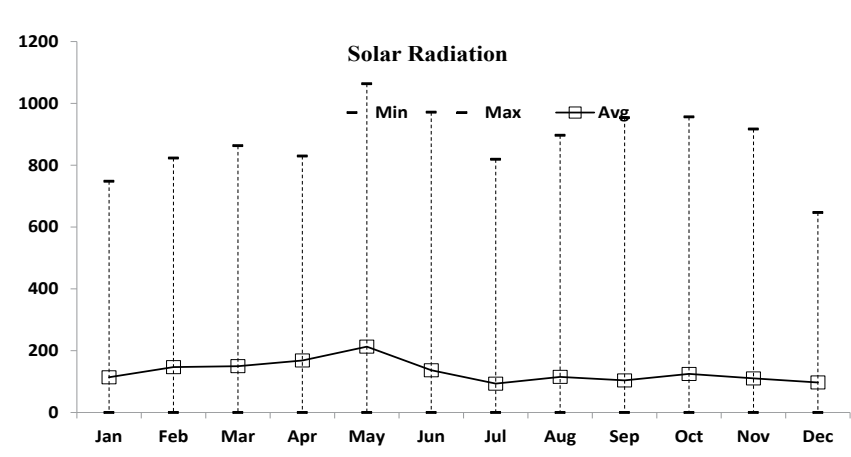

Figure 3: Seasonal variation in solar radiation at the Monitoring site.
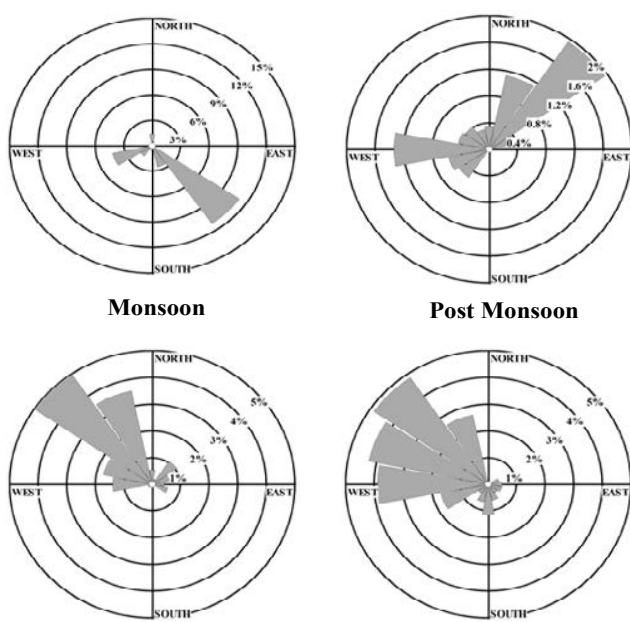

Winter

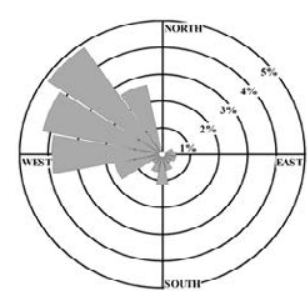

Summer

Figure 4: Wind rose for seasons during the sampling duration. 
in this season. The daily average temperature then tends to cool down in November marking the onset of winter (December to February). The temperature in winter occasionally drops below $10^{\circ} \mathrm{C}$ but that is only for a short period of time.

\section{Site description}

The site selected for the present study is Mumbai city which is also known as financial capital of India. It is one of the four Mega cities of the country (Figure 5). The city is located on the western coast of India and exhibits typical urban characteristics such as high population density and enormous vehicular population. The site is surrounded on the western side by Arabian Sea, while the southern side is marked by residential and commercial areas of the city. A small portion on the south-west of the city is covered by a bay (Mahim Bay); whereas the suburban areas cover the adjoining boundaries on the northern and eastern sides of the city. The international airport of the city (circled) is located between the North and North-East side. A major roadway named Western express highway which experiences a heavy traffic during peak hours runs very close to the monitoring site.

The continuous air quality monitoring station is located at Govt. Polytechnic, Bandra (Figure 5). It is located away from the coastline in order to avoid influence of rapid changes in the wind pattern. A major roadway near the monitoring site enables to trap the pollution from vehicular sources. The city also has a small industrial complex at Andheri which is located on the northern side of the monitoring site. Therefore, it is important to study the formation of ground level ozone in the city which has a high population density and dynamic metrological conditions.

\section{Database and analysis}

For the present study, hourly average data for a period of two years (from $1^{\text {st } J a n ~} 2008$ to $31^{\text {st }}$ Dec 2009) has been considered. This secondary data has been obtained from the Maharashtra Pollution Control Board (MPCB) monitoring station. A continuous monitoring system was installed at the present site in the year 2007, manufactured by Chemtrols and provides data on instantaneous and hourly basis for the pollutants monitored.

The meteorological parameters and primary precursor pollutants which are considered to be responsible for the formation of GLO have been considered. The data for oxides of Nitrogen (NOx), carbon monoxide (CO) and benzene has been obtained. Along with this, the meteorological data for temperature, solar radiation, relative humidity, wind-speed and wind-direction has also been considered. The hourly average data has been grouped into four seasons to study the seasonal variation and was further used to administer the correlation tests. For calculating wind direction mode was preferred over mean values. The reason to opt the mode value of wind direction is that, if the records would have been averaged the results would show a completely different pattern for wind direction. The percentage of missing values in summer, monsoon, post monsoon and winter accounted for less than $2 \%$. The missing values in the data were replaced with median value for the corresponding pollutant in that particular season. The sampling was not carried out from $9^{\text {th }}$ Jan 2009 to $15^{\text {th }}$ Jan 2009 due to maintenance of instruments. Similarly, the data where in the readings for three or more parameters is not obtained for more than three hours has been deleted from the data set. The hourly data obtained from MPCB was divided into four seasons and was subjected to the four-sigma test in order to remove outliers. It was found that the outliers amounted only $3 \%$ of the entire data set combining all the parameters. The data thus obtained was subjected to Pearson's correlation test in SPSS software version 17. The values falling out of the range were replaced with the median value for the respective season. The median value was preferred over mean or mode for replacing the outliers because the mean calculate was arithmetic mean and in case of mode, multiple modes existed in the data sets. To evaluate the effects of meteorological parameters, wind rose was plotted using the software WR PLOT version 7.0.

\section{Results}

After applying the outlier test the highest concentration of the parameters during the monitoring period are reported. The descriptive statistics of precursor pollutants and meteorological parameters are described in Table 1.

From the results it can be inferred that the annual hourly average for ozone during the monitoring period was $27.87 \mu \mathrm{g} / \mathrm{m}^{3}$ and $34.93 \mu \mathrm{g} /$ $\mathrm{m}^{3}$ in 2008 and 2009 respectively. It was observed that the hourly ozone concentration exceeded the Central Pollution Control Board's norm $\left(180 \mu \mathrm{g} / \mathrm{m}^{3}\right)$ on 191 occasions which accounts to $1 \%$ of the total no.of observations.

Whereas the 8 hourly permissible limit $\left(100 \mu \mathrm{g} / \mathrm{m}^{3}\right)$ was exceeded 88 times in the monitoring period. It should be noted that ground level ozone concentration remained under the norms during the summer and monsoon seasons while the highest concentration of ozone was observed during post monsoon season $\left(252.4 \mu \mathrm{g} / \mathrm{m}^{3}\right)$. At the same time, the number of hourly and eight hourly exceedances have more than doubled in 2009 as compared to 2008 .

In case of $\mathrm{NO}_{\mathrm{x}}$ and $\mathrm{CO}$, the annual averages in 2008 and 2009 were computed to be $65.54 \mu \mathrm{g} / \mathrm{m}^{3}, 2.06 \mu \mathrm{g} / \mathrm{m}^{3}$ and $74.26 \mu \mathrm{g} / \mathrm{m}^{3}, 2.26 \mu \mathrm{g} / \mathrm{m}^{3}$ respectively which marginally exceed the annual average standards prescribed by CPCB (NOx: $40 \mu \mathrm{g} / \mathrm{m}^{3}$ and CO: $2 \mu \mathrm{g} / \mathrm{m}^{3}$ ).

The diurnal variations in concentration of ozone concentration are depicted in Figure 6. For the purpose of evaluating the influence

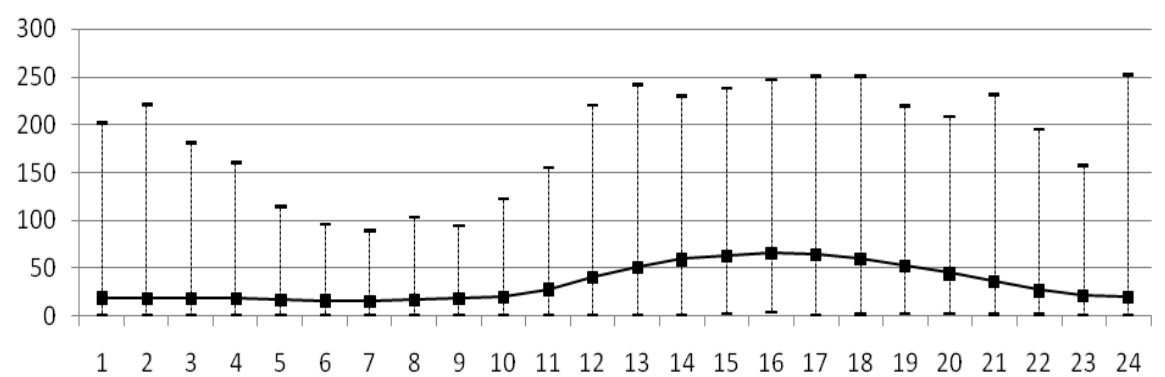

Figure 5: Average Diurnal variation of ground level ozone during the monitoring period at Mumbai with minimum and maximum concentration. 


\begin{tabular}{|c|c|c|c|c|c|c|c|c|}
\hline & & NOx $\left(\mu \mathrm{g} / \mathrm{m}^{3}\right)$ & $\mathrm{CO}\left(\mu \mathrm{g} / \mathrm{m}^{3}\right)$ & $\mathrm{O}_{3}\left(\mu \mathrm{g} / \mathrm{m}^{3}\right)$ & Benzene $\left(\mu \mathrm{g} / \mathrm{m}^{3}\right)$ & $\begin{array}{c}\text { Temperature } \\
\left({ }^{\circ} \mathrm{C}\right)\end{array}$ & $\begin{array}{c}\text { Solar Radiation } \\
\left(\mathbf{W} / \mathbf{M}^{2}\right)\end{array}$ & RH (\%) \\
\hline \multirow{4}{*}{ Summer } & Min & 3.2 & 0.5 & 1 & 0 & 21.70 & 0 & 20.7 \\
\hline & Max & 226 & 6.2 & 141.5 & 33 & 40.60 & 1063.70 & 96.5 \\
\hline & Avg. & 44.1 & 2.6 & 27.6 & 2.7 & 29.69 & 177.08 & 67.73 \\
\hline & SD & 38.1 & 0.9 & 23.1 & 4.3 & 2.91 & 264.99 & 12.16 \\
\hline \multirow{4}{*}{ Monsoon } & Min & 0.5 & 0.1 & 1 & 0 & 24.00 & 0.00 & 53.9 \\
\hline & Max & 188 & 4.7 & 73.4 & 15 & 35.30 & 971.50 & 99.9 \\
\hline & Avg. & 40.3 & 1.3 & 19.1 & 1.4 & 28.43 & 112.01 & 86.36 \\
\hline & SD & 30.2 & 0.5 & 12.9 & 1.9 & 2.08 & 194.05 & 9.47 \\
\hline \multirow{4}{*}{$\begin{array}{c}\text { Post } \\
\text { Monsoon }\end{array}$} & Min & 2.9 & 0.1 & 1 & 0.04 & 20.80 & 0.00 & 15.4 \\
\hline & Max & 546 & 7.6 & 252 & 51.4 & 38.90 & 956.30 & 99.9 \\
\hline & Avg. & 114 & 2.3 & 48.1 & 3.3 & 28.94 & 117.56 & 65.52 \\
\hline & SD & 99 & 1.3 & 44.9 & 4.4 & 3.44 & 209.49 & 18.42 \\
\hline \multirow{4}{*}{ Winter } & Min & 1.9 & 0.1 & 1 & 0 & 7.3 & 0 & 15.3 \\
\hline & Max & 422 & 7.1 & 228 & 46.6 & 37.6 & 823.3 & 96.2 \\
\hline & Avg. & 96.2 & 2.2 & 41.6 & 6.1 & 25.69 & 118.62 & 58.67 \\
\hline & SD & 80.9 & 1.2 & 44.6 & 6.9 & 4.13 & 194.82 & 14.71 \\
\hline
\end{tabular}

Table 1: Descriptive Statistics of Parameters.

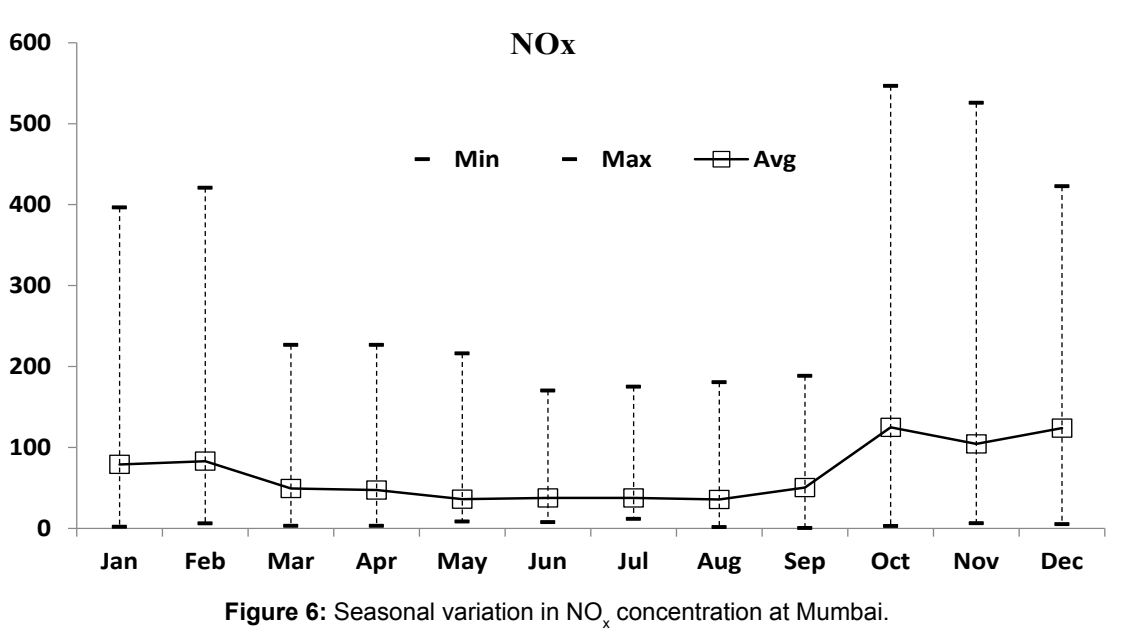

of precursor pollutants and metrological parameters on formation of ozone, Pearson's correlation test was administered to the data set. As stated in section 5 the data divided was into four seasons and the resultant diurnal average was considered for the correlation test.

\section{Oxides of nitrogen $\left(\mathrm{NO}_{\mathrm{x}}\right)$}

The highest one hourly concentration of $\mathrm{NO}_{\mathrm{x}}$ was observed in the post monsoon season. The values were observed to be consistently high in both the months (Oct. and Nov.) ranging between 525-547 $\mu \mathrm{g} /$ $\mathrm{m}^{3}$. The daily ( $24 \mathrm{hr}$.) average limit of $\left(80 \mu \mathrm{g} / \mathrm{m}^{3}\right)$ was computed to be exceeding on 77 days in the same season which accounts $63 \%$ of the days in the post monsoon season. The minimum concentration of the season was noted be around $2.9 \mu \mathrm{g} / \mathrm{m}^{3}$. The lowest concentration was observed during 04:00 hrs. in the early morning. The monthly average for both the months in the season remained above $100 \mu \mathrm{g} / \mathrm{m}^{3}$.

In the winter season, it was experienced that, $60 \%$ of the time the concentration of $\mathrm{NO}_{\mathrm{x}}$ exceeded the CPCB standard $\left(80 \mu \mathrm{g} / \mathrm{m}^{3}\right)$. This observation can said to be similar as in the case of post-monsoon season. The average hourly maximum concentration in this season was noted to be $422 \mu \mathrm{g} / \mathrm{m}^{3}$. This highest hourly average was observed during 09:00 hrs in the morning same as in case of the post monsoon season, while the lowest value of the season was measured to be 1.9 $\mu \mathrm{g} / \mathrm{m}^{3}$ around 14:00 hr. during afternoon. The concentration of $\mathrm{NO}_{\mathrm{x}}$ is observed to decrease drastically in the summer and monsoon seasons, decreasing up to $50 \%$ as compared to earlier seasons.

The lowest concentration in the summer season is observed to be $3.2 \mu \mathrm{g} / \mathrm{m}^{3}$ while the highest concentration was noted to be $226.8 \mu \mathrm{g} /$ $\mathrm{m}^{3}$. It is noteworthy to mention that the lowest concentration was experienced during the afternoon around 15:00 hr. while the highest concentration was noted around 09:00 hr. in the morning which are considered to have high vehicular activity. The seasonal average value for the season was computed to be $44.2 \mu \mathrm{g} / \mathrm{m}^{3}$. It is important to note that the instances of the daily limit being exceeded were observed only 3 times in the season which is lowest amongst all of the seasons. The monsoon experienced a low concentration of less than $2 \mu \mathrm{g} / \mathrm{m}^{3}$ during the afternoon around 14:00hr. The highest concentration of $\mathrm{NO}_{\mathrm{x}}$ in this season was noted be around $185 \mu \mathrm{g} / \mathrm{m}^{3}$ during early morning hours at 07:00 a.m. The average concentration of $\mathrm{NO}_{x}\left(40.31 \mu \mathrm{g} / \mathrm{m}^{3}\right)$ in this season is calculated to be lowest as compared to rest of the seasons. The daily standard was observed to be exceeding only 8 times in the season. 


\section{Carbon monoxide (CO)}

As in the case of $\mathrm{NO}_{\mathrm{x}}$ the highest concentration of $\mathrm{CO}$ was measured in the post monsoon season as provided in Table 1 earlier. The average hourly maximum concentration in the season was noted to be $4.7 \mu \mathrm{g} / \mathrm{m}^{3}$ at 00:00 during the night. The minimum concentration in the season was noted be less than $1 \mu \mathrm{g} / \mathrm{m}^{3}$. The maximum average hourly concentration in the winter season reached up to $7.1 \mu \mathrm{g} /$ $\mathrm{m}^{3}$ while the minimum concentration remained below $1 \mu \mathrm{g} / \mathrm{m}^{3}$. The highest concentration was observed around 10:00 in the morning and the minimum concentration was experienced during evening around 18:00 hr. in the evening. The maximum hourly average concentration of $\mathrm{CO}$ in the summer season was measured to be around $6.2 \mu \mathrm{g} / \mathrm{m}^{3}$ around 11:00 a.m. in the morning while the concentration was experienced to drop below $1 \mu \mathrm{g} / \mathrm{m}^{3}$ several times during the season. The highest hourly average concentration of $\mathrm{CO}$ in the monsoon season reached up to 4.7 $\mu \mathrm{g} / \mathrm{m}^{3}$ in the night while the lowest concentration was observed to be under $1 \mu \mathrm{g} / \mathrm{m}^{3}$ at several times.

The above results indicate that the availability of precursor pollutants in the post-monsoon was higher as compared to the rest of the seasons. The reasons for the high concentration are discussed in the later section of the study after presenting the results for variation in the concentration of ground level ozone in different seasons.

\section{Ground Level Ozone}

The variations in concentration of ozone in each season are presented as follows

\section{Post monsoon}

It was observed that there is a sharp increase in the concentration of NOx in the post monsoon season (Figure 7). The seasonal average concentration of the season was calculated to be $114 \mu \mathrm{g} / \mathrm{m}^{3}$ which is nearly three times that of summer and monsoon. The peak hourly concentration recorded in the entire monitoring season was observed in this season $\left(546 \mu \mathrm{g} / \mathrm{m}^{3}\right)$. The peak of hourly average concentration of NOx was observed around 09:00 hrs in the morning. This can be related to high traffic and low solar intensity which negates the chances of photo-dissociation. The concentration of $\mathrm{CO}$ was noted to be very low as compared to rest of the pollutants. The seasonal variation in concentration of $\mathrm{CO}$ is depicted in Figure 8. The post monsoon season also has the highest number of one hourly (60 times) and eight hourly (25 times) exceedances. The diurnal variations in post monsoon season are depicted in Figure 9. Which shows maximum and minimum concentrations of the time of day in the season.

It is important to note that the highest hourly concentration of $252.1 \mu \mathrm{g} / \mathrm{m}^{3}$ in the post monsoon season was observed at 00:00 hrs

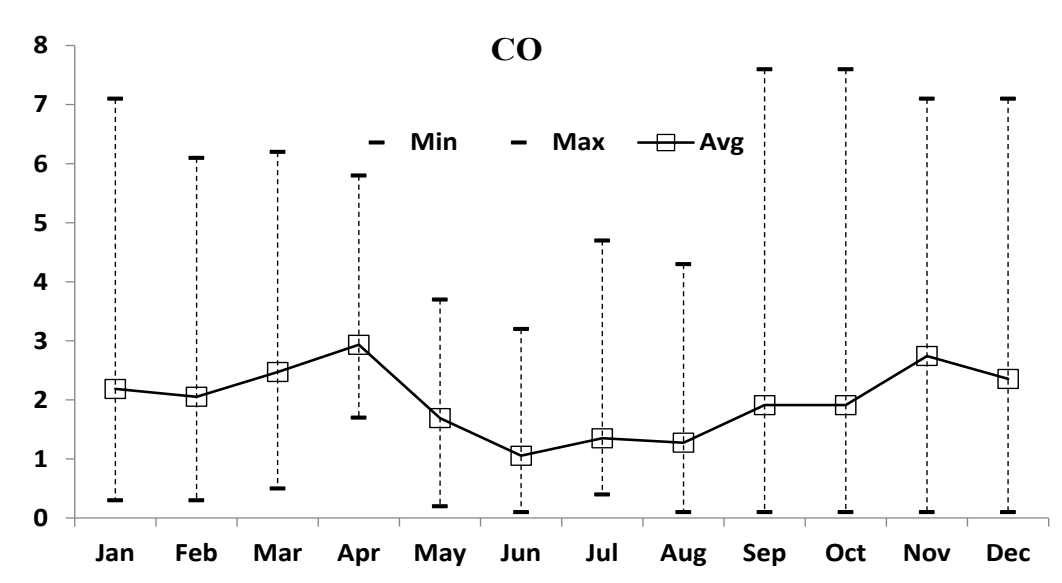

Figure 7: Seasonal variations in concentration of carbon monoxide (CO) at Mumbai.

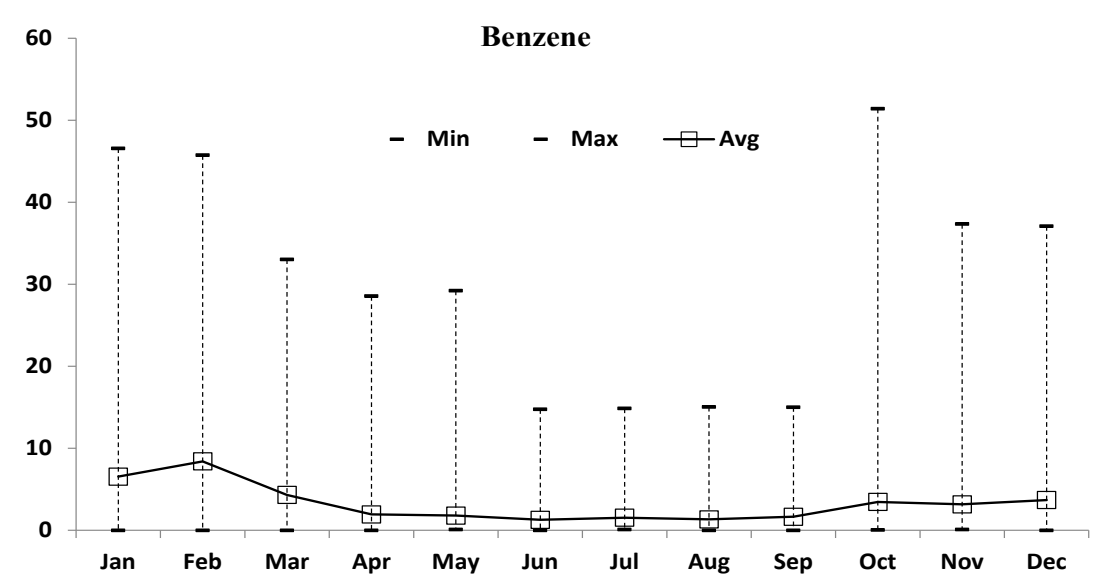

Figure 8: Seasonal variation in concentration of Benzene at monitoring site 


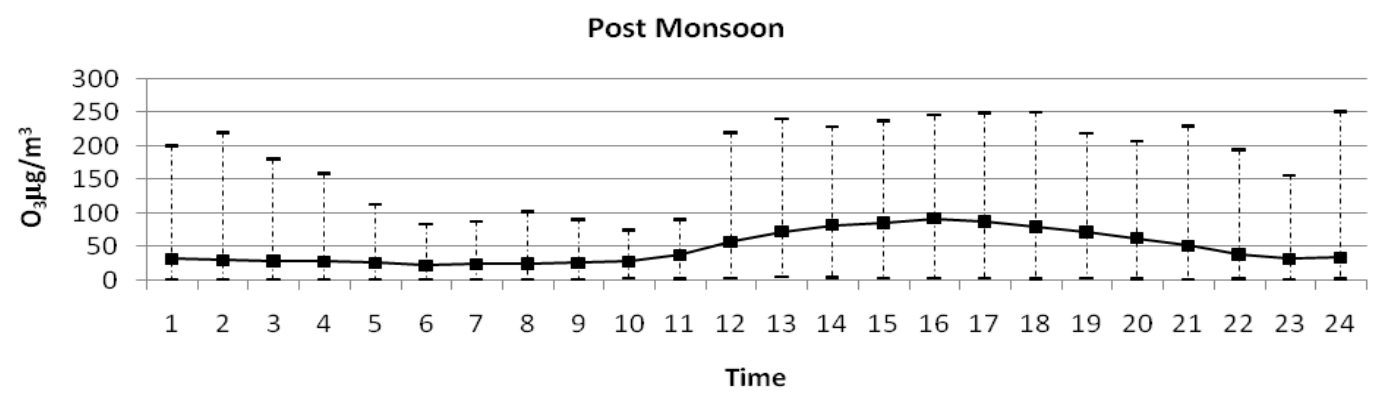

Figure 9: Variations in ground level ozone concentration in the post monsoon season with minimum and maximum concentration.

\begin{tabular}{|c|c|c|c|c|c|c|c|}
\hline & Ozone & $\mathrm{CO}$ & NOx & Temp & Solar Rad. & $\mathbf{R H}$ & WD \\
\hline Ozone & 1 & $-0.804^{* *}$ & $-0.939^{* *}$ & $0.814^{* *}$ & $0.408^{*}$ & $-0.647^{\star *}$ & $0.645^{* *}$ \\
\hline $\mathrm{CO}$ & & 1 & $0.834^{* *}$ & $-0.599^{* *}$ & -0.348 & $0.503^{*}$ & $-0.569^{* *}$ \\
\hline NOx & & & 1 & $-0.643^{* *}$ & -0.206 & $0.440^{*}$ & $-0.504^{*}$ \\
\hline Benz & & & & $-0.697^{* *}$ & $-0.430^{*}$ & $0.626^{* *}$ & $-0.612^{* *}$ \\
\hline Temp & & & & 1 & $0.821^{* *}$ & $-0.963^{* *}$ & $0.721^{* *}$ \\
\hline Solar Rad. & & & & & 1 & $-0.923^{* *}$ & $0.529^{* *}$ \\
\hline $\mathrm{RH}$ & & & & & & 1 & $-0.701^{* *}$ \\
\hline WD & & & & & & & 1 \\
\hline
\end{tabular}

Note: Where, $\mathrm{CO}=$ Carbon monoxide, $\mathrm{NOx}=$ Oxides of Nitrogen, $\mathrm{RH}=$ Relative Humidity, Temp $=$ Temperature, Solar Rad. $=$ Solar radiation and WD $=$ Wind Direction respectively.

Table 2: Pearson's Correlation of Ozone with precursor pollutants and meteorological parameters in Post Monsoon Season.

\section{Winter}

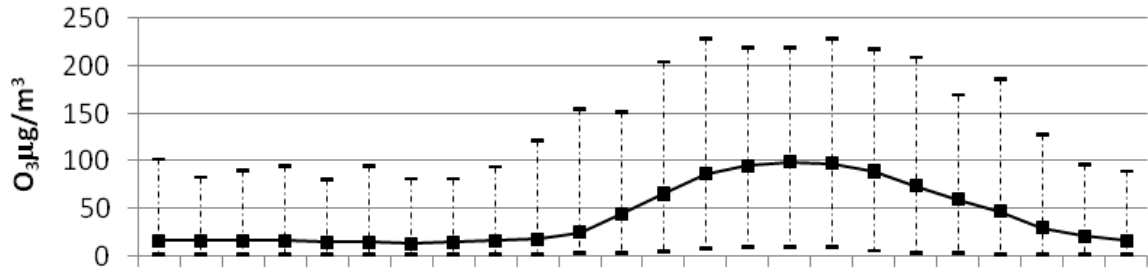

$1 \quad 2 \quad 3 \quad 4 \quad 5 \quad 6 \quad 7 \quad 8 \quad 9101112131415161718192021222324$

Time

Figure 10: Variations in ground level ozone concentration in the winter season with minimum and maximum concentration.

during the night. The lowest concentration was reported as $1 \mu \mathrm{g} / \mathrm{m}^{3}$ and it was mostly observed during the night time. The peak of hourly average in the season was recorded at 16:00 $\mathrm{hr}$. and was noted to be $92.02 \mu \mathrm{g} / \mathrm{m}^{3}$.

The correlation between ozone and selected parameters is shown in Table 2. According to this analysis, a strong negative correlation of ozone with $\mathrm{NO}_{x}(-0.939)$ and $\mathrm{CO}(-0.804)$ is observed. This finding indicates that concentration of precursor pollutants not only plays an important role in the formation of ozone but also in its destruction. Amongst the metrological parameters except for relative humidity the correlation of ozone with reset of the parameters considered for the study was found to be positive. Among the metrological parameters the highest correlation was observed with temperature (0.814). The correlation of ozone with solar radiation, relative humidity, wind direction and wind speed was estimated to be $0.408,-0.647,0.645$ and 0.808 respectively.

It may be reckoned that the predominant wind direction for the post monsoon season is north and north east (as provided in the wind rose plot in Figure 4.

\section{Winter}

The next highest concentration of ozone was found in the winter season. The average concentrations and minimum and maximum values for ground level ozone are plotted in Figure 10. High ozone concentrations are observed during the afternoon in this season with peak reaching at 14:00 hrs. The season is marked with low temperatures, especially during the night. Since there is limited amount of thermal inversion in this season the pollutants tend to be trapped near the ground level. Therefore this season also experiences high pollution episodes. The highest hourly concentration $\left(228 \mu \mathrm{g} / \mathrm{m}^{3}\right)$ in this season was experienced close to the maxima of the post monsoon season; while the lowest concentration was observed to be $1 \mu \mathrm{g} / \mathrm{m}^{3}$.

In the winter season, the correlation of ozone with the precursor pollutants is strongly negative as shown in Table 3 and is above -0.9 suggesting their importance. The correlation of ozone with the 
Citation: Marathe SA, Murthy S (2015) Seasonal Variation in Surface Ozone Concentrations, Meteorology and Primary Pollutants in Coastal Mega City of Mumbai, India. J Climatol Weather Forecasting 3: 149. doi:10.4172/2332-2594.1000149

Page 7 of 10

\begin{tabular}{|c|c|c|c|c|c|c|c|}
\hline & Ozone & $\mathrm{CO}$ & NOx & Temp & Solar Rad. & RH & WD \\
\hline Ozone & 1 & $-0.938^{* *}$ & $-0.917^{* *}$ & $0.800^{* *}$ & $0.468^{*}$ & $-0.644^{* *}$ & $0.922^{* *}$ \\
\hline $\mathrm{CO}$ & & 1 & $0.957^{* *}$ & $-0.714^{* *}$ & -0.389 & $0.552^{* *}$ & $-0.875^{* *}$ \\
\hline NOx & & & 1 & $-0.704^{* *}$ & -0.312 & $0.517^{* *}$ & $-0.834^{* *}$ \\
\hline Benz & & & & $-0.705^{* *}$ & -0.320 & $0.537^{* *}$ & $-0.842^{* *}$ \\
\hline Temp. & & & & 1 & $.834^{* *}$ & $-0.967^{* *}$ & $0.735^{* *}$ \\
\hline Solar Rad. & & & & & 1 & $-0.896^{* *}$ & $0.449^{*}$ \\
\hline $\mathrm{RH}$ & & & & & & 1 & $-0.593^{* *}$ \\
\hline WD & & & & & & & 1 \\
\hline
\end{tabular}

Table 3: Pearson's Correlation of Ozone with precursor pollutants and meteorological parameters in Winter Season.

Summer

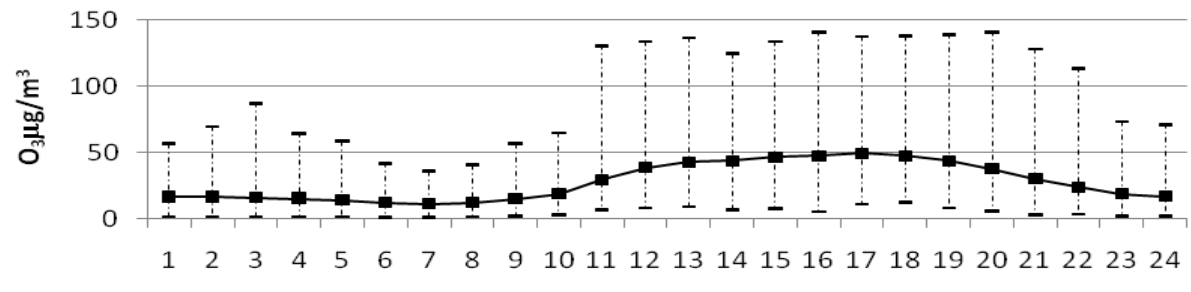

Time

Figure 11: Variations in ground level ozone concentration in the summer season with minimum and maximum concentration.

\begin{tabular}{|c|c|c|c|c|c|c|c|}
\hline & Ozone & $\mathrm{CO}$ & NOx & Temp. & Solar Rad. & $\mathbf{R H}$ & WD \\
\hline Ozone & 1 & $-0.668^{* *}$ & $-0.644^{* *}$ & $0.850^{* *}$ & $0.619^{* *}$ & $-0.818^{* *}$ & $0.875^{\star *}$ \\
\hline $\mathrm{CO}$ & & 1 & $0.922^{* *}$ & -0.404 & -0.326 & 0.319 & $-0.437^{\star}$ \\
\hline NOx & & & 1 & $-0.410^{*}$ & -0.283 & 0.328 & $-0.422^{*}$ \\
\hline Benz & & & & -0.140 & -0.036 & 0.064 & -0.300 \\
\hline Temp. & & & & 1 & $0.888^{* *}$ & $-0.989^{* *}$ & $0.855^{*+}$ \\
\hline Solar Rad. & & & & & 1 & $-0.853^{* *}$ & $0.647^{* *}$ \\
\hline $\mathrm{RH}$ & & & & & & 1 & $-0.876^{* *}$ \\
\hline WD & & & & & & & 1 \\
\hline
\end{tabular}

Table 4: Pearson's Correlation of Ozone with precursor pollutants and meteorological parameters in Summer Season.

meteorological parameters is different in this season as compared to that in the monsoon. In winter ozone exhibits a strong positive correlation with wind direction (0.922) clearly indicating the role of wind in transportation of pollutants. It needs to be confirmed whether the precursor pollutants are transported or the ozone formed at some other location is being transported directly to the monitoring site. Moreover the correlation of ozone with wind speed helps in strengthening the above findings.

\section{Summer}

The maximum hourly average concentration of ground level ozone was observed to be around $141.5 \mu \mathrm{g} / \mathrm{m}^{3}$ at $16: 00 \mathrm{hrs}$. The seasonal variation in the concentration is depicted in Figure 11. The concentration can be observed to have decreased as a result increase in the photochemical breakdown of ground level ozone. The same case may be applicable for the precursor pollutants as the rate of their dissociation may exceed the rate of formation of ground level ozone. In this season the correlation of ozone was negative with the precursor pollutants but not strong as compared to that in the case of post monsoon and winter seasons. The correlation for the summer season is provided in Table 4. The correlation of ozone with wind direction is positive similar to the earlier seasons. It should be noted that the correlation values between wind direction and ozone are higher as compared to that in the post monsoon season but the highest concentration of ozone was still observed in the post monsoon season. The correlation of ozone with solar radiation also appears to be strongly positive as compared to the rest of the seasons which suggests that higher solar intensity favors the formation of GLO. The correlation of relative humidity with ozone is strongly negative indicating that high relative humidity leads to decrease in ozone concentration. As depicted in Figure 8 it can be observed that the average relative humidity during the daytime in the summer season is higher as compared to the post monsoon and winter season which supports the above findings for destruction of ozone.

\section{Monsoon}

The average concentration for the monsoon season is depicted in the Figure 12. During Monsoon the weather is largely cloudy and hence there is minimal availability of solar intensity. Also, the concentration of pollutants is fairly low making it the cleanest season of the year in tropical conditions. The highest concentration of ozone in this season was observed to be $73 \mu \mathrm{g} / \mathrm{m}^{3}$, but it is also important to note that the average concentration never exceeded $30 \mathrm{n} \mu \mathrm{gm} /{ }^{3}$. The peak ozone concentrations are observed during the afternoon at 13:00 hrs which is a peculiar feature of the season. The correlation of ozone with selected parameters for the monsoon season is provided in Table 5.

It is important to highlight that the correlation of ozone with NOx (0.1) was found to be weakly positive which is not observed in any of the studies considered so far. The correlation with $\mathrm{CO}$ was observed 


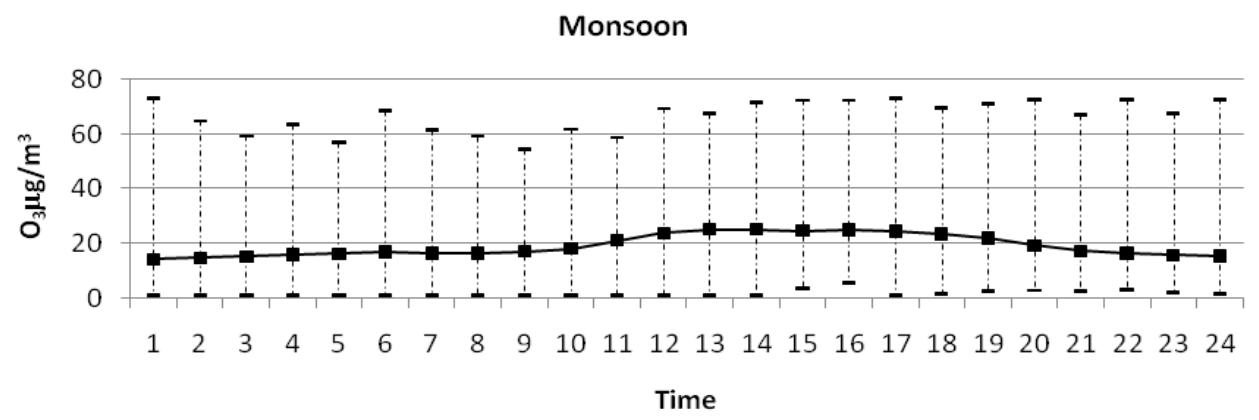

Figure 12: Variations in ground level ozone concentration in the monsoon season with minimum and maximum concentration.

\begin{tabular}{|c|c|c|c|c|c|c|c|}
\hline & Ozone & CO & NOx & Temp & Solar Rad. & RH & WD \\
\hline Ozone & 1 & -0.250 & 0.101 & $0.943^{* *}$ & $0.817^{* *}$ & $-0.948^{* *}$ & $0.758^{* *}$ \\
\hline $\mathrm{CO}$ & & 1 & $0.830^{* *}$ & -0.163 & 0.006 & 0.251 & -0.308 \\
\hline NOx & & & 1 & 0.208 & 0.219 & -0.170 & -0.089 \\
\hline Benz & & & & $-0.620^{* *}$ & $-0.433^{*}$ & $0.670^{* *}$ & $-0.614^{* *}$ \\
\hline Temp & & & & 1 & $0.906^{* *}$ & $-0.988^{* *}$ & $0.751^{* *}$ \\
\hline Solar Rad. & & & & & 1 & $-0.838^{* *}$ & $0.704^{* *}$ \\
\hline $\mathrm{RH}$ & & & & & & 1 & $-0.736^{* *}$ \\
\hline WD & & & & & & & 1 \\
\hline
\end{tabular}

Table 5: Pearson's Correlation of Ozone with precursor pollutants and meteorological parameters in Monsoon Season.

to be weakly negative. The correlation of precipitation (rainfall) was observed to be negligible and hence not considered in the study. The correlation of ozone with the meteorological parameters can be observed to increase in this season. Amongst the meteorological parameters, the correlation with Temperature was found to be strongly positive $(0.943)$ while the correlation with relative humidity appeared to be strongly negative having the value of -0.948 . The correlation of solar intensity can be observed to be doubled as compared to that in the post monsoon or winter season and is also the strongest. The correlation of ozone with wind speed remains strongly positive but less than in the case of summer or winter season.

\section{Discussion}

Since there is no annual average prescribed by the CPCB for GLO it becomes difficult for comparison with other pollutants.

Trend of ground level ozone in India: It is documented that ozone concentration may increase as a result of transport of precursor pollutant mass [7]. In a similar context the study by Naja and Lal [9] report an increase in $\mathrm{O}_{3}$ concentration by $1-2 \%$ per year. This study was conducted for the city of Ahmedabad.

In yet another study for the city of Ahmedabad, elevated level of $\mathrm{O}_{3}$ concentration up to $110 \mathrm{ppbv}$ were reported [7]. At rural sites it was observed that ozone concentrations were high during the afternoon hours (ibid). According to the study the increased ozone concentration may have occurred due to the trans-boundary carriage of polluted air from the up wind urban areas. Surface $\mathrm{O}_{3}$ concentration in the city of Pune was reported to be around $46-120 \mu \mathrm{g} / \mathrm{m}^{3}$; the increase of daytime maximum $\mathrm{O}_{3}$ concentration being attributed to the increased vehicular traffic density. For the same city during 2001-2005, concentration of ozone was reported to be as high as $180 \mu \mathrm{g} / \mathrm{m}^{3}$ and the permissible limits were repeatedly breached [18]. In rural areas of western India, the ozone concentrations were reported to be high during 2002-2004 in the summer season. The study attributed this to natural as well as anthropogenic activities. In the city of Delhi, Singh et al. (1997) reports that ozone concentration during the winter season of 1993were between $68-252 \mu \mathrm{g} / \mathrm{m}^{3}$ (averaged for $30 \mathrm{~min}$. time interval). It can be said that due to higher the temperatures in summer the ozone and precursor pollutants both undergo photo dissociation at a faster rate than their production or emissions and hence are unable to contribute for higher concentration of ozone. The lowest concentration of ozone is observed in monsoon season which is well in accordance with several other studies from the Indian subcontinent $[7,9,10,18]$.

The studies conducted by Sarkar and Agrawal [13] report the impact of ozone concentration on plants. These studies consider short monitoring duration of one or two seasons which are important for life cycle of plants. The seasonal trend cannot be affirmed from such type of studies as they do not record the data for long term duration. The studies reported so far are conducted in different climatic backgrounds. In addition these studies do not have homogeneity in terms of spatiotemporal land use and emission sources. Other studies which have conducted monitoring for all the seasons have reported highest ozone concentration in summer season (REFS.), while some studies have reported highest concentrations in winter season.

Few studies have reported high ozone concentrations in the month of October (Post Monsoon season) which were conducted at Varanasi [13]. But the study was conducted to assess impacts of ambient ozone levels on productivity and other parameters of two Indian cultivars of rice and the reasons for high concentration were not discussed in detail. Highest GLO concentrations from few cities of the country are reported in Table 6 along with the observations from the present study. From the city of Pune which is situated in the western part of India, the highest concentration for GLO was reported to be around $80-100 \mu \mathrm{g} / \mathrm{m}^{3}$ during summer whereas the lowest concentration was reported around $8-14 \mu \mathrm{g} / \mathrm{m}^{3}$ during the monsoon [18]. Other studies conducted in the city of Ahmadabad reported peak concentrations of $93.8 \pm 27.6 \mu \mathrm{g} / \mathrm{m}^{3}$ [9]. There is a slight variation in ozone concentration in other cities, Delhi $\left(68-252 \mu \mathrm{g} / \mathrm{m}^{3}\right)$ in winter and at high altitudinal 
Citation: Marathe SA, Murthy S (2015) Seasonal Variation in Surface Ozone Concentrations, Meteorology and Primary Pollutants in Coastal Mega City of Mumbai, India. J Climatol Weather Forecasting 3: 149. doi:10.4172/2332-2594.1000149

Page 9 of 10

\begin{tabular}{|c|c|c|c|c|c|c|}
\hline Sr. No. & City & Author and Year of Study & Highest conc. $\left(\mu \mathrm{g} / \mathrm{m}^{3}\right)$ & Season & $\begin{array}{c}\text { Lowest } \\
\text { conc. } \mu \mathrm{g} / \mathrm{m}^{3} \text { ) }\end{array}$ & Season \\
\hline 1 & Pune & Debaje and Kakade, 2009 & $80-100$ & Summer & $8-14$ & Monsoon \\
\hline 2 & Ahmadabad & Lal et al., 2000 & $93.8 \pm 27.6$ & Winter & - & Monsoon \\
\hline 3 & Delhi & Singh et al., 1997 & $68-252$ & Winter & - & Monsoon \\
\hline 4 & Mt. Abu & Naja et al., 2003 & 206 & Winter & - & Monsoon \\
\hline 5 & Mumbai & Present Study & 252.10 & Post -Monsoon & 1 & Monsoon \\
\hline
\end{tabular}

Note: The studies which have considered data for all the seasons in the year are considered for the comparison.

Table 6: Comparison of ozone concentration in selected cities of India and Mumbai (present study).

zone of Mt. Abu $\left(206 \mu \mathrm{g} / \mathrm{m}^{3}\right)$ where maximum concentration was also reported in winter season [7].

In the present study the highest concentration of ground level ozone is observed in the post monsoon season unlike studies discussed above. This can be said to be associated with the change in the wind direction and availability of precursor pollutants. These findings are corroborated by the study conducted for the city of Delhi (Chelani, 2009). It can be said that as the site is near to the coast, horizontal mixing of the air can be experienced throughout the day as result of strong wind flow which is experienced due to land breeze and sea breeze effect. It should also be noted that the relative humidity is observed to be very low throughout the season. The presence of relative humidity indicates availability of $\mathrm{OH}$ radicals. These radicals are supposed to interfere with ozone formation by scavenging the $\mathrm{O}_{3}$ molecules. It is obvious that the ozone formation is not possible in the absence of precursor pollutants. There are two possible sources for the emission of precursor pollutants, one of them being the air traffic from the nearby international airport and the other could be due to vehicular traffic from the western express highway running close to the monitoring site.

\section{Conclusion}

Based on the above findings it can be concluded that the process of formation and destruction of ozone is dynamic and changes not only seasonally but diurnally. Also it is important to note that ozone formation is influenced by availability of precursor pollutants under favorable meteorological conditions. The present study highlights some important findings which are not reported so far from Indian subcontinent. The highest ozone concentration was observed in the post monsoon season unlike other studies in which the peak concentrations were reported in either winter or summer season. Secondly the correlation of ozone with NOx was found to be weakly positive in the monsoon season which is also a rear phenomenon. Moreover, the concentration of $\mathrm{NOx}$ and $\mathrm{CO}$ were found to be higher during the early morning and evening during the rush hours of traffic suggesting the influence of high vehicular activity around the monitoring site. The location of the Sahara international airport and the positive correlation of ozone with wind direction in the post monsoon season indicate that the precursor pollutants are being transported to the monitoring site. This can be justified by the fact that highest concentrations for the selected pollutants have been observed in the post monsoon season. Thus it could be concluded the reasons for high ozone concentration in the post monsoon season are the effect of anthropogenic emissions. Moreover the present study highlights the problem of transport of pollutants at local level.

\section{Acknowledgement}

We are thankful to MPCB for providing us the required data and NITIE for enabling us with facilities for computational work.

\section{Appendix I}

\section{Chemistry of Ground level Ozone:}

The available literature suggests that, the process of ozone formation is nonlinear and has multiple channels $[14,19]$. The process of ozone formation can be explained as under:

1. Photolysis of Ozone: In this case the ozone molecules undergo photolysis under UV rays shorter than $320 \mathrm{~nm}$ to dissociate into active oxygen atom and oxygen molecule [3]. The reactive molecule reacts with either water vapour to form hydroxyl radical or with any inert molecule to produce $\mathrm{O}_{3}$. The inert molecules are mostly $\mathrm{N}_{2}$ (ibid).

$$
\begin{aligned}
& \mathrm{O}_{3}+\mathrm{hu} \rightarrow \mathrm{O}\left({ }^{1} \mathrm{D}\right)+\mathrm{O}_{2} \\
& \mathrm{O}\left({ }^{1} \mathrm{D}\right)+\mathrm{H}_{2} \mathrm{OOH}+\mathrm{OH} \\
& \mathrm{O}\left({ }^{1} \mathrm{D}\right)+\mathrm{M} \rightarrow \mathrm{O}\left({ }^{3} \mathrm{P}\right)+\mathrm{M} \\
& \mathrm{O}\left({ }^{3} \mathrm{P}\right)+\mathrm{O}_{2}+\mathrm{M} \rightarrow \mathrm{O}_{3}+\mathrm{M}
\end{aligned}
$$

2. Hydroxyl radical Channel: The hydroxyl radicals present in the atmosphere prominently react with either photo-chemically active methane or carbon monoxide atoms which leads to formation of ground level ozone [2-4]. It is noteworthy that the low concentration of $\mathrm{NO}_{\mathrm{x}}$ in the atmosphere and other precursors can lead to the removal of ozone [3].

3. The $\mathrm{NO}_{\mathrm{x}}$ channel: The $\mathrm{NO}$ molecules undergo oxidation to form $\mathrm{NO}_{2}$. This conversion is a result of actions of oxidizing agents like hydroxyl radicals or ozone itself. The photo-dissociation of $\mathrm{NO}_{2}$ is explained in the equations (5) to (8).

$$
\begin{aligned}
& \mathrm{NO}+\mathrm{OH} \rightarrow \mathrm{NO}_{2}+\mathrm{H} \\
& \mathrm{NO}_{2}+\mathrm{hu} \rightarrow \mathrm{NO}+\mathrm{O}\left({ }^{3} \mathrm{P}\right)[\lambda \leq 400 \mathrm{~nm}] \\
& \mathrm{O}\left({ }^{3} \mathrm{P}\right)+\mathrm{O}_{2} \rightarrow \mathrm{O}_{3} \\
& \mathrm{NO}+\mathrm{O}_{3} \rightarrow \mathrm{NO}_{2}+\mathrm{O}_{2}
\end{aligned}
$$

4. The VOC and nm VOC channel: The reaction of NO with ozone is suppressed by presence of VOCs as the affinity of hydrocarbons towards NO appears to be higher than ozone. This leads to formation of $\mathrm{NO}_{2}$. At times the hydrocarbons are supposed to compete with ozone leading to destruction of ozone molecules.

$$
\begin{aligned}
& \mathrm{RH}+\mathrm{OH} \rightarrow \mathrm{R}^{\circ}+\mathrm{H}_{2} \mathrm{O} \\
& \mathrm{R}^{\circ}+\mathrm{O}_{2} \rightarrow \mathrm{RO}_{2}^{\circ} \\
& \mathrm{RO}_{2}^{\circ}+\mathrm{NO} \rightarrow \mathrm{RO}^{\circ}+\mathrm{N}_{2}
\end{aligned}
$$

It may be taken into consideration that the studies also suggest ozone formation has been reported to be water vapour dependent [3]. The water vapour in the atmosphere is usually affected by relative humidity and temperature.

Relative humidity and temperature vary spatially and temporarily making ozone formation a local phenomenon. The studies reported documented for ozone in India do not discuss the role of relative humidity in detail. 
Citation: Marathe SA, Murthy S (2015) Seasonal Variation in Surface Ozone Concentrations, Meteorology and Primary Pollutants in Coastal Mega City of Mumbai, India. J Climatol Weather Forecasting 3: 149. doi:10.4172/2332-2594.1000149

\section{References}

1. Liu SC, Trainer M, Fersenfeld FC, Parrish DD, Williams EJ, et al. (1987) Ozone production in the rural troposphere and the implications from regional and global ozone distributions, J Geophys Res. 92: 4191-4207.

2. World Bank Group (1998) Handbook of GLO Pollution Prevention and Abatement Handbook World Bank Group Effective.

3. Royal Society (2008) Ground-level ozone in the 21st century: future trends, impacts and policy implications, Science Policy Report.

4. Guttikunda Sarath (2009) Photochemistry of Air pollution in Delhi, India: A monitoring based analysis, SIM-air Working Paper series 25-2009.

5. WHO (2006) Air quality guidelines: global update 2005, particulate matter, ozone, nitrogen dioxide and sulphur-dioxide. WHO Regional Office for Europe: Copenhagen.

6. Chameides WL, Xingsheng Li, Xiaoyan Tang, Xiuji Zhou, Luo Chao, et al (1999) Is ozone pollution affecting crop yields in China. Geophysical Research Letters 26: 867-870.

7. Naja M, Lal D Chand (2003) Diurnal and seasonal variabilities in surface ozone at a high altitude site Mt Abu in India. Atmospheric Environment 37: 4205-4215.

8. Debaje SB, Jadhav DB (1999) An Eulerian photochemical model for tropospheric ozone over the tropics. Current Science 77: 1537-1541.

9. Lal, Naja,Subbaraya (2000) Seasonal variations in surface ozone and its precursors over an urban site in India. Atmospheric Environment 34: 27132724.
10. Debaje SB, Jeya kumar SJ, Ganesan K, Jadhav D, Seetaramayya P (2003) Surface ozone measurements at tropical rural coastal station Tranquebar, India Atmospheric Environment 37: 4911-4916.

11. Salve PR, Satapathy DR, Katpatal YB, Wate SR (2007) Assessing Spatial Occurrence of GLO around Coal Mining Areas of Chandrapur District, Maharashtra, India Environ Monit Assess133: 87-98.

12. David Liji M, Nair Prabha R (2010) Influence of aerosols on near surface ozone mixing ratio at Tropical coastal environment. IASTA 2010 Conference on Aerosols and clouds: Climate change perspectives 28: 155.

13. Sarkar, Agrawal, Chemtrols (2012) Ambient Air Quality Station.

14. WHO (World Health Organization) (1979) "Photochemical Oxidants." Environmental Health Criteria 7 Geneva.

15. WHO (1987) Air Quality Guidelines for Europe. Copenhagen: WHO Regional Office for Europe.

16. EEA (2007) Air Pollution in Europe 1990-2004. EEA Report No2/2007. European Environment Agency: Copenhagen

17. Kley D, Geiss H (1994) Tropospheric ozone at elevated sites and precursor emissions in the United States and Europe. Atmos. Environ 28: 149-158.

18. Debaje, Kakade (2009) Surface ozone variability over western Maharashtra, India. Journal of Hazardous Materials 161: 686-700.

19. Duenas C, Fernandez MC, Canete S, Carretero J, Liger E (2002) Assessment of ozone variations and meteorological effects in an urban area in the Mediterranean Coast The Science of the Total Environment 299: 97-113.
Citation: Marathe SA, Murthy S (2015) Seasonal Variation in Surface Ozone Concentrations, Meteorology and Primary Pollutants in Coastal Mega City of Mumbai, India. J Climatol Weather Forecasting 3: 149. doi:10.4172/2332 2594.1000149

\section{OMICS International: Publication Benefits \& Features}

Unique features:

Increased global visibility of articles through worldwide distribution and indexing

Showcasing recent research output in a timely and updated manner

Special issues on the current trends of scientific research

Special features:

700 Open Access Journals

50,000 Editorial team

Rapid review process

Quality and quick editorial, review and publication processing

Indexing at PubMed (partial), Scopus, EBSCO, Index Copernicus, Google Scholar etc.

Sharing Option: Social Networking Enabled

Authors, Reviewers and Editors rewarded with online Scientific Credits

Better discount for your subsequent articles

Submit your manuscript at: http://www.omicsonline.org/submission/ 